\title{
Interfacing a Salamander Brain with a Salamander-like Robot: Control of Speed and Direction with Calcium Signals from Brainstem Reticulospinal Neurons
}

\author{
Dimitri Ryczko, Robin Thandiackal, Auke J. Ijspeert, Member, IEEE
}

\begin{abstract}
An important topic in designing neuroprosthetic devices for animals or patients with spinal cord injury is to find the right brain regions with which to interface the device. In vertebrates, an interesting target could be the reticulospinal (RS) neurons, which play a central role in locomotor control. These brainstem cells convey the locomotor commands to the spinal locomotor circuits that in turn generate the complex patterns of muscle contractions underlying locomotor movements. The $R S$ neurons receive direct input from the Mesencephalic Locomotor Region (MLR), which controls locomotor initiation, maintenance, and termination, as well as locomotor speed. In addition, RS neurons convey turning commands to the spinal cord. In the context of interfacing neural networks and robotic devices, we explored in the present study whether the activity of salamander RS neurons could be used to control off-line, but in real time, locomotor speed and direction of a salamander robot. Using a salamander semiintact preparation, we first provide evidence that stimulation of the RS cells on the left or right side evokes ipsilateral body bending, a crucial parameter involved during turning. We then identified the RS activity corresponding to these steering commands using calcium $\left(\mathrm{Ca}^{2+}\right)$ imaging of $\mathrm{RS}$ neurons in an isolated brain preparation. Then, using a salamander robot controlled by a spinal cord model, we used the ratio of $\mathrm{RS} \mathrm{Ca}^{2+}$ signals on left and right sides to control locomotion direction by modulating body bending. Moreover, we show that the robot locomotion speed can be controlled based on the amplitude of the $\mathrm{Ca}^{2+}$ response of $\mathrm{RS}$ cells, which is controlled by MLR stimulation strength as recently demonstrated in salamanders.
\end{abstract}

\section{INTRODUCTION}

Brain-machine interfaces (BMIs) are increasingly used in fundamental research in order to better understand the neural principles underlying motor control. The development of such devices is historically linked to basic research examining the role of the motor cortex in controlling the direction and velocity of upper limb movements (e.g. [1], [2]). First developed in rodents [3] and monkeys (e.g. [4], [5]), BMIs are now used in the field of assistive technology to improve motor function of the upper limbs in patients suffering from devastating disablements like tetraplegia (e.g. [6], [7]). BMIs controlling lower limbs are also developed to improve locomotor function, but still to a much lesser extent [8], [9], [10], [11], [12], [13], for review see [14]. To restore

*Research supported by the Swiss National Science foundation (Project 140714).

D. Ryczko is with Université de Montréal, Montréal (QC), H3C 3J7 Canada (e-mail:dimitri.ryczko@gmail.com).

R. Thandiackal, and A.J. Ijspeert are with the EPFL, Ecole Polytechnique Fédérale de Lausanne, 1015 Lausanne Switzerland (e-mail: robin.thandiackal@epfl.ch, auke.ijspeert@epfl.ch). locomotion with BMIs, some authors proposed to use signals of the primary motor cortex and somatosensory areas recorded with implanted electrodes from monkeys during walking to control a biped robot/lower limb exoskeleton [9]. Other proposed to use recordings of the fronto-parietal cortical networks obtained with scalp electroencephalography in humans during walking [15]. A study proposed to use primary motor cortex recordings obtained during forelimb walking to control electrical stimulation of the hindlimb muscles in spinalized rats [12]. Finally another study proposed to use electromyographic recordings of the forelimb to control electrical stimulation of the lumbosacral spinal cord, in order to activate the spinal locomotor circuits controlling the hindlimbs [13]. However, some of these approaches rely on forelimb motor activity and could thus not be applied to tetraplegia. The other approaches rely on motor cortex recordings during locomotor movements. This is consistent with e.g. the motor cortex showing activity modulation related to modification of hindlimb motor pattern in the cat [e.g. 16]. It is true that the motor cortex is involved in visuo-motor coordination and precision walking through direct projection over RS cells or spinal interneurons, as shown by the work of Drew and colleagues [for review see 17]. However, it is worth to note that kittens decorticated during their first weeks of life can walk, trot or gallop and show complex goal-directed behaviors, indicating that other networks (i.e. brainstem networks, see below) generate the locomotor commands [18]. Moreover, whether activity patterns of motor cortex neurons could be used in cases where no forelimb activity is available to elicit rhythmic feedback to the cortices remains to be resolved.

In contrast, the activity of brainstem locomotor networks that conveys the descending locomotor commands to spinal cord circuits in vertebrates (for review see [19]), was rarely used to control a locomotor device. This may related to the low accessibility of these networks, located deep in the brain. However, it is noteworthy that the brainstem contains the reticulospinal (RS) neurons that play a crucial role in activating locomotion. These hindbrain neurons send descending projections to the spinal locomotor circuits. The RS cells receive direct inputs from a locomotor center located at the border between the midbrain and the hindbrain, called the Mesencephalic Locomotor Region (MLR). The MLR is dedicated to initiating and finely controlling locomotor speed and gait transitions. Such locomotor center was first discovered in cats [20] and then in all vertebrates tested (for review see [19]). The RS neurons also receive inputs from different sensory modalities and are responsible for steering and equilibrium control [21]. 


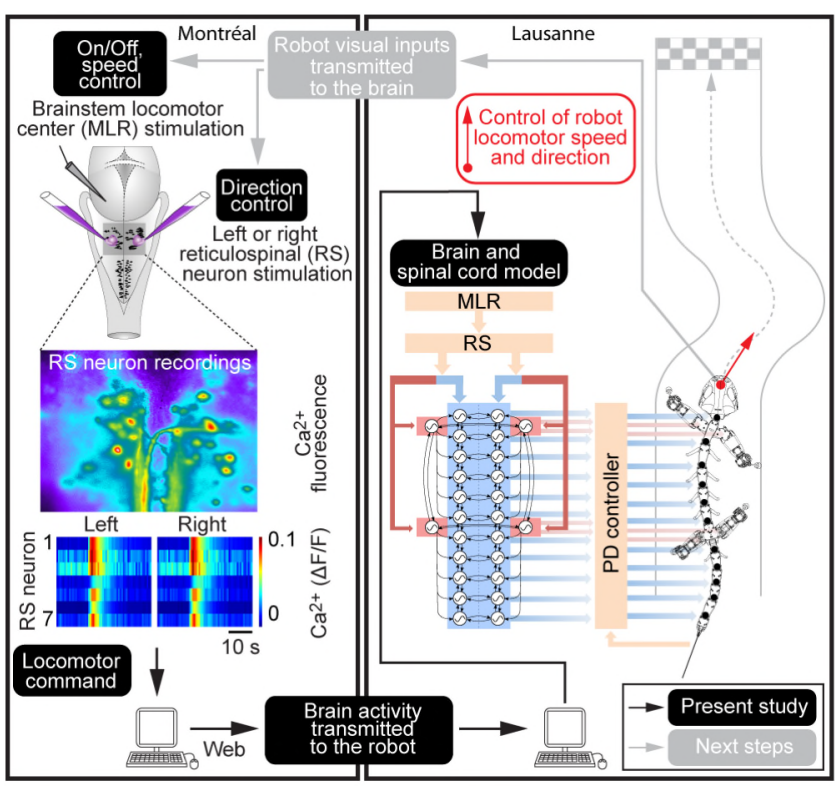

Figure 1. Interfacing a salamander brain with a salamander robot. $\mathrm{Ca}^{2+}$, calcium; $\Delta \mathrm{F} / \mathrm{F}$, relative change in fluorescence; MLR, Mesencephalic Locomotor Region; PD, proportional-derivative; RS, reticulospinal. In black: in this paper; in gray: future work.

Thus, the RS cells are considered as the "final common pathway for locomotion" (for review see [22]). Interfacing at the brainstem level is thus interesting because RS activity allows one to read out important information such as speed and steering commands, which result of the computations done by higher brain areas involved in locomotor control. To our knowledge, only two studies connected lamprey brainstem RS neurons to a two-wheeled robot in a closedloop paradigm, in order to study the dynamics and plasticity of such a neuro-robotic system [23], [24].

Here we examined whether signals from brainstem RS neurons can be used to control locomotor speed and direction of a robotic device. To this end we used the salamander as an animal model, where the brainstem networks are easily accessible experimentally. In salamanders as in other vertebrates, the basic muscle contractions are programmed by a specialized neural network in the spinal cord called the Central Pattern Generator (CPG, see [25]), which controls axial and limb movements [26], [27], [28], [29]. This network integrates sensory signal and is under the control of brainstem locomotor networks. Salamanders have a MLR, and stimulation of this region evokes walking in a semi-intact preparation [30]. Increasing the strength of the stimulation increases locomotor speed. Further increase induced a transition to swimming. The MLR does so by sending bilaterally symmetrical descending glutamatergic input to RS neurons [31], which in turn project to the spinal CPG [32], [33], [34]. RS are active during locomotion [35], [34], and their activity can be precisely controlled by the strength of MLR stimulation [36], [37], [31].

In addition, the salamander locomotor system was modeled at different levels of abstraction, from abstract coupled oscillators [38] to more realistic neural networks [39], [40]. We here used a modified version of the modeling presented in [38] in order to integrate the $\mathrm{RS} \mathrm{Ca}^{2+}$ activities as command signals, off-line, but in real time. This work is the first step of a project aiming at feeding back to the brain the visual field from the robot, in order to develop a closedloop approach where the brain and the robot could autonomously follow a path or reach a target (Fig. 1). Moreover, the present proof of concept shows that the $\mathrm{Ca}^{2+}$ activity of RS cells can be used to control locomotor speed and direction, and may thus be relevant to control a whole body locomotor exoskeleton.

\section{Procedures}

\section{A. Animals}

All procedures conformed to the guidelines of the Canadian Council on Animal Care and were approved by the animal care and use committees of the Université de Montréal (QC, Canada). Care was taken to minimize the number of animals used and their suffering. The experiments were performed on 6 juvenile salamanders (Notophthalmus viridescens) (Snout-vent length 40-50 $\mathrm{mm}$ ) purchased from Connecticut Valley Biological Supply (MA, USA) or Boreal Science (ON, Canada). The animals were kept in aerated water at $20^{\circ} \mathrm{C}$ and fed weekly with frozen bloodworms.

\section{B. Surgical procedures}

The procedures were similar to that previously used [30], [31]. Briefly, the animals were anesthetized by immersion in a $0.2 \%$ aqueous solution of tricaine methanesulphonate (MS-222, $200 \mathrm{mg} / \mathrm{L}$ ). They were transferred to a dissection dish filled with a cold $\left(8-10{ }^{\circ} \mathrm{C}\right)$ and oxygenated Ringer's solution (in mM: $130 \mathrm{NaCl}, 2.1 \mathrm{KCl}, 2.6 \mathrm{CaCl}_{2}, 1.8 \mathrm{MgCl}_{2}$, 4 HEPES, 4 dextrose, and $1 \mathrm{NaHCO}_{3}(\mathrm{pH}$ 7.4)). After evisceration, the brain and first segment of the spinal cord were exposed dorsally. The low jaw, the forelimbs, as well as the brain rostral to the mesencephalon were removed.

\section{C. $\mathrm{Ca}^{2}$ imaging}

$\mathrm{Ca}^{2+}$ imaging experiments were performed on 4 isolated brain preparations. The procedure was similar to that described elsewhere [41], [42], [31]. Briefly, a transverse section was made at the level of the first spinal segments and the caudal part of the body was removed. RS neurons were retrogradely labeled by placing $\mathrm{Ca}^{2+}$ green dextran amine crystals at the level of the first spinal segment. The preparation was then placed overnight in a chamber perfused with a cold $\left(8-10^{\circ} \mathrm{C}\right)$ oxygenated Ringer's solution to allow the dye to retrogradely label RS neurons. The following day, the brain preparation was placed in a recording chamber perfused with a cooled $\left(8-10{ }^{\circ} \mathrm{C}\right)$ oxygenated Ringer's solution $(4 \mathrm{~mL} / \mathrm{min})$. A stimulation electrode or pipette was placed in the MLR on one side. The stimulation site was identified on the basis of previous studies describing the distribution of MLR neurons [30], [31]. An optimal focus was chosen for imaging the RS neurons of the middle reticular nucleus (mRN) on the basis of previous studies describing the distribution of RS neurons in salamanders [33], [31]. The changes in fluorescence in RS cells were measured in regions of interests manually delineated around the RS cells bodies filled with the $\mathrm{Ca}^{2+}$ green dextran amine. The responses of RS cells to MLR stimulation or local 
microinjections of D,L-glutamate were recorded with a Nikon epifluorescent microscope coupled with a CCD video camera (Photometrics CoolSNAP HQ; Roper Scientific). The $\mathrm{Ca}^{2+}$ responses were expressed as relative changes in fluorescence $(\Delta F / F$, see [31]). Baseline was defined as the average fluorescence of the cell body before stimulation. Data was acquired with Metafluor and analysed with Sigmaplot and Matlab.

\section{Salamander kinematics on semi-intact preparation}

Two animals were used to perform movement analysis following microinjections of D,L-glutamate over the RS neurons of the mRN. We used the semi-intact salamander preparation previously developed by Cabelguen and colleagues [30]. The dissection was similar to that of the isolated brain preparation except that the caudal part of the body was kept intact. The preparation was then transferred to a recording chamber perfused with a cold $\left(8-10{ }^{\circ} \mathrm{C}\right)$ oxygenated Ringer's solution ( $4 \mathrm{~mL} / \mathrm{min})$. The ventral cranium was pinned in the rostral part of the chamber, whereas the caudal body part was free to move in the bath. A glass micropipette filled with D,L-glutamate was placed over the RS cells of the left or right $\mathrm{mRN}$ for local microinjections. The evoked body movements were recorded (30 frames/s) with a camera (HDR-XR200; Sony) positioned $1 \mathrm{~m}$ above the recording chamber. The movements were analyzed with a custom Matlab script previously used for lamprey kinematics [41], [43], [44]. Briefly, virtual markers were distributed equidistantly along the body dorsal midline using geometrical analysis of the body. Body bending angle was monitored frame by frame between the lines drawn by two successive markers at the level of the mid-trunk, at rest and after stimulation of the mRN with D,L-glutamate.

\section{E. Drugs}

To chemically stimulate RS neurons or the MLR, a Ringer's solution containing $2.5 \mathrm{mM}$ of D,L-glutamate was injected locally onto RS neurons or in the MLR as previously described [31], [42], [44]. Drugs were injected using a glass micropipette (diameter $10-20 \mu \mathrm{m}$ ) by applying pressure pulses (3-4 PSI) of 20 to $100 \mathrm{~ms}$ duration with a Picospritzer microinjection system. The injected volumes were calculated as previously (e.g. [31], [44]) by measuring the volume of a droplet in the air following a single pressure pulse, multiplied by the number of pressure pulses used during the injection. The number of moles was then calculated.

\section{F. Electrical stimulation}

The MLR was stimulated to generate precisely controlled and reproducible locomotor-related activation of the RS neurons. The MLR was stimulated with homemade glass coated tungsten electrodes (0.7-3.1 M $\Omega, 10-35 \mu \mathrm{m}$ exposed tip) as previously done in salamanders [30], [31]. Stimulation was delivered with a GRASS stimulator coupled to a Grass PSIU6 photoelectric isolation unit. The MLR was stimulated with trains of electrical square pulses (2-ms duration) applied with a frequency of $5 \mathrm{~Hz}$ for $30 \mathrm{~s}$. A pause of 3 to 5 min was allowed between two train stimulations. The stimulation intensities ranged from 1.5 to $3 \mu \mathrm{A}$.

\section{G. Spinal cord model for controlling the robot}

To control the salamander robot we used a slightly modified version of the model described in [38]. It is based on abstract coupled oscillators distributed along the spinal cord, with different sets of oscillators controlling the trunk, tail and limbs. The corresponding topology of the network is shown in Fig. 1. The states of each oscillator are defined as follows:

$\dot{\theta}_{i}=2 \pi f_{i}+\sum_{j} w_{i j} r_{i} \sin \left(\theta_{j}-\theta_{i}-\phi_{i j}\right)$
$\dot{r}_{i}=a\left(R_{i}-r_{i}\right)$
$x_{i}=r_{i}\left(1+\cos \left(\theta_{i}\right)\right)$

, where $\theta_{i}, r_{i}$ and $x_{i}$ denote the phase, amplitude and output of the i-th oscillator. $f_{i}$ denotes the intrinsic frequency, $R_{i}$ the nominal amplitude, $w_{i j}$ the coupling weight and $\phi_{i j}$ the phase bias between oscillators.

The corresponding parameters of the model are given in TABLE I.

TABLE I. MODEL PARAMETERS

\begin{tabular}{|l|l|l|l|}
\hline \multicolumn{1}{|c|}{ Parameter } & \multicolumn{1}{c|}{ Value } & \multicolumn{1}{c|}{ Parameter } & \multicolumn{1}{c|}{ Value } \\
\hline$f_{\text {limb,max }}{ }^{1}$ & $0.8 \mathrm{~Hz}$ & $f_{\text {body }}{ }^{2}$ & $1.2 \mathrm{~Hz}$ \\
\hline$R_{\text {limb }}$ & 1 & $R_{\text {body,max }}$ & 0.15 \\
\hline$a$ & 4 & & \\
\hline$w_{\text {body, updown }}$ & 5 & $\phi_{\text {limb,contra }}$ & $\pi$ \\
\hline$w_{\text {body,leftright }}$ & 5 & $\phi_{\text {limb,ipsi }}$ & $6 \pi / 5$ \\
\hline$w_{\text {limb }}$ & 20 & $\phi_{\text {limb-body }}$ & $\pi$ \\
\hline$w_{\text {limb-body }}$ & 50 & $\phi_{\text {body, contra }}$ & $\pi$ \\
\hline$w_{\text {body-limb }}$ & 5 & $\phi_{\text {body, ipsi }}$ & $2 \pi / 11$ \\
\hline
\end{tabular}

1. body: denotes oscillators of the trunk and tail 2. limb: denotes limb oscillators

As shown in Fig. 1 the simulated spinal oscillator network receives input from the average $\mathrm{Ca}^{2+}$ activity of $\mathrm{RS}$ neurons located on the left side ( $d_{L}$ : left drive) and on the right side $\left(d_{R}:\right.$ right drive) of the salamander brain. These biological signals are influencing the intrinsic frequencies and the nominal amplitudes. We compute the corresponding quantities as follows:

$R_{\text {body,left }}=d_{L} R_{\text {body,max }}$
$R_{\text {body,right }}=d_{R} R_{\text {body,max }}$
$f_{\text {limb }}=\frac{1}{2}\left(d_{L}+d_{R}\right) f_{\text {limb,max }}$

Consequently, higher drives increase the limb frequency and turning is induced by asymmetric drives. In the present study, turning involves two synergistic mechanisms as described in previous modeling studies. Firstly, asymmetric drives induce body bending in the trunk and tail, with an increased bending angle ipsilaterally to an increased RS activity (see [45]). In addition, the drive signals influence the stride lengths of the forelimbs, where higher drives lead to decreased stride length on the corresponding side (see [46]). 


\section{H. Robot}

For the robot experiments, Pleurobot [47] was used. Pleurobot is a salamander-like robot that has been developed based on detailed cineradiographic recordings of Pleurodeles waltl. in different media such as water and land. Its optimized spinal segmentation, and its high number of degrees of freedom (11 for the spine and 4 per leg) allow to very closely reproduce various salamander gaits. The robot uses servomotors (Dynamixel MX 64), which are controlled in the present study via position control depending on the oscillator outputs. The control signal for the spinal joints is computed as the difference of two lateral body oscillator outputs $\left(x_{\text {left }}-x_{\text {right }}\right)$. The intra-limb coordination of the 4 degrees of freedom is implemented as suggested in [47] with an inverse kinematics algorithm, that allows to compute the corresponding joint angles in the limbs for a specified foot trajectory. The corresponding parameters are given in TABLE II. Finally the phase of each limb is determined by the phase of the corresponding limb oscillator.

TABLE II. FOOT TRAJECTORIES FOR INVERSE KINEMATICS

\begin{tabular}{|l|l|c|l|}
\hline Parameter & \multicolumn{1}{|c|}{ Value } & Parameter & \multicolumn{1}{|c|}{ Value } \\
\hline T1 ${ }^{1}$ (front) & {$[0.3,0.18,-0.15] \mathrm{m}$} & $\alpha_{1}$ & $45^{\circ}$ \\
\hline $\mathrm{T} 2$ (front) & {$[0.1,0.2,-0.07] \mathrm{m}$} & $\alpha_{2}$ & $-45^{\circ}$ \\
\hline T3 (front) & {$[0,0,0.18,-0.15] \mathrm{m}$} & $\beta_{1}$ & $-30^{\circ}$ \\
\hline T1 (hind) & {$[0.2,0.15,-0.17] \mathrm{m}$} & $\beta_{2}$ & $-30^{\circ}$ \\
\hline T2 (hind) & {$[0.0,0.22,-0.07] \mathrm{m}$} & & \\
\hline T3 (hind) & {$[-0.1,0.15,-0.17] \mathrm{m}$} & & \\
\hline
\end{tabular}

1. Parameters T1, T2, T3 correspond to characteristic points of the foot trajectory. $\alpha_{\mathrm{i}}$ and $\beta_{\mathrm{i}}$ describe tilting angles of the trajectory [47]

\section{Robot kinematics}

Robot movements were recorded with a GOPRO Hero 2 from a top view. The post-processing included correction of the lens distortion in Adobe Premier Pro as well as manual tracking (at $2.4 \mathrm{~Hz}$ ) of the forelimb girdle and hindlimb girdle with the help of a custom script in Matlab 2015b. The line between the girdles was then used to determine the instantaneous movement direction. Subsequently, turning angles could be computed as relative angles between current and initial moving direction. For the speed estimation, the progression of the forelimb girdle was used.

\section{RESULTS}

\section{A. Control of body bending evoked by $m R N$ stimulation}

It is not yet known in salamanders how steering commands are generated. In lampreys, modulation of the body bending angle on the horizontal plane is used during turning [21]. Such phenomenon is associated with increased RS activity ipsilateral to the turn during in vivo [21] and fictive locomotion [48]. A similar steering mechanism was proposed to occur in salamanders in previous modeling studies [45], [46]. Using salamander semi-intact preparations $(\mathrm{n}=2)$, we here examined whether specific stimulation of left or right sides of the $\mathrm{mRN}$ with glutamate was sufficient to control body bending. We stimulated RS neurons with glutamate, as RS neurons receive glutamatergic inputs from the MLR [31] and probably from relay neurons of various
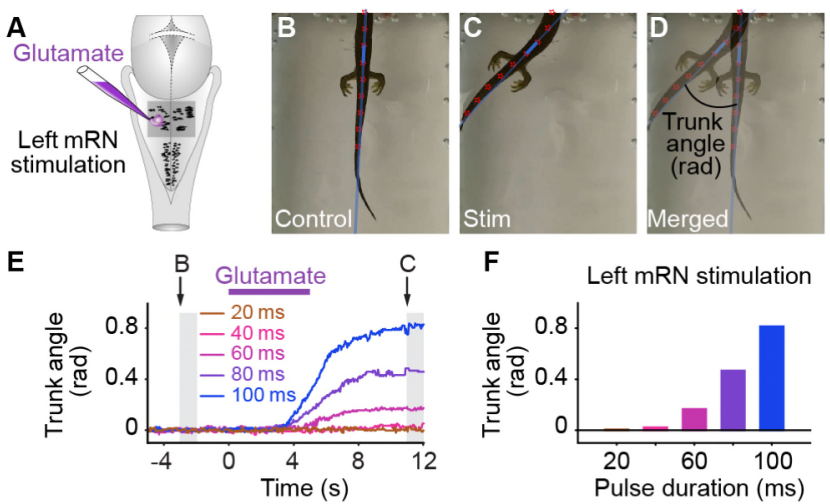

F Left mRN stimulation
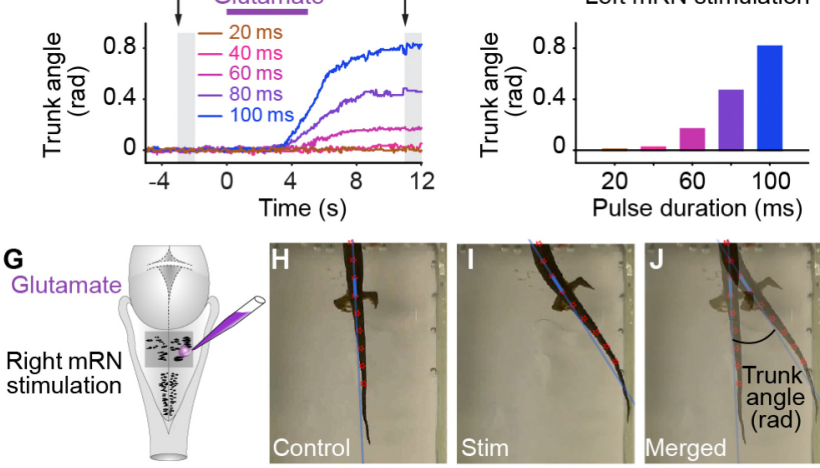

$\mathbf{K}$
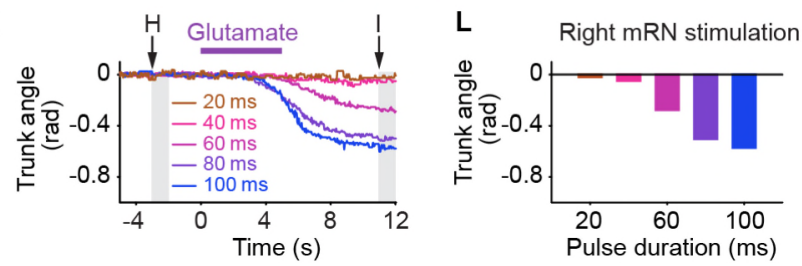

Figure 2. Steering commands evoked by left or right chemical stimulation of reticulospinal (RS) cells of the middle rhombencephalic nucleus (mRN) in a semi-intact preparation of salamander. A: dorsal view of a salamander brain. 0.91 to 30.37 pmol of D,L-glutamate $(2.5 \mathrm{mM} 10$ pulses, $2 \mathrm{~Hz}, 3-4$ PSI, 20-100 ms pulses, 0.36 to $12.1 \mathrm{~nL}$ per injection) were selectively injected locally over the left or right RS cells. B-D: Comparison of body orientation $2 \mathrm{~s}$ before glutamate injection (B), and $11 \mathrm{~s}$ after (C). E: Frameby-frame measurement of the body bending angle (in radians) evoked by glutamate microinjections (See Procedures). F: Maximum bending angle values, measured $11 \mathrm{~s}$ post glutamate microinjection in all cases. G-L: Same representation as in A-F.

sensory modalities like e.g. the visual system (i.e. tectal inputs [49], see also e.g. [50] in lampreys). Local microinjections of 0.09 to $30.37 \mathrm{pmol}$ of D,L-glutamate $(2.5$ $\mathrm{mM}, 1-10$ pulses, $2 \mathrm{~Hz}, 3-4$ PSI, 20-100 ms pulses, 0.04-12.1 $\mathrm{nL}$ per injection) over the left $\mathrm{mRN}$ (Fig. 2A) evoked an increased bending of the body ipsilaterally to the microinjection (Fig. 2B-D). The body remained in the new position after such stimulation (Fig. 2C). The amplitude of the bending angle increased with the amount of glutamate microinjected over the mRN (Fig. 2E-F). Conversely, when microinjecting D,L-glutamate over the right side of the $\mathrm{mRN}$ using the same microinjection parameters, bending was selectively elicited toward the right side. Again, the bending angle increased with the amount of glutamate injected over the mRN. Similar results were obtained with the other preparation tested. Altogether this indicated that precise steering commands can be generated by selective stimulation of left and right RS neurons in salamanders.

\section{B. $\mathrm{RS} \mathrm{Ca}^{2+}$ activity underlying steering commands}

We examined in isolated brain preparations $(n=3)$ the type of $\mathrm{RS} \mathrm{Ca}^{2+}$ responses evoked by the stimulation evoking left and right body bending in the semi-intact preparations. To this end, we recorded in identified mRN RS neurons the 
A

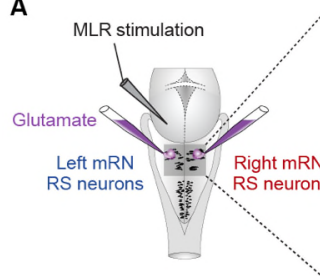

B Puff on $\begin{gathered}\text { Puff on } \\ \text { right mRN }\end{gathered}$
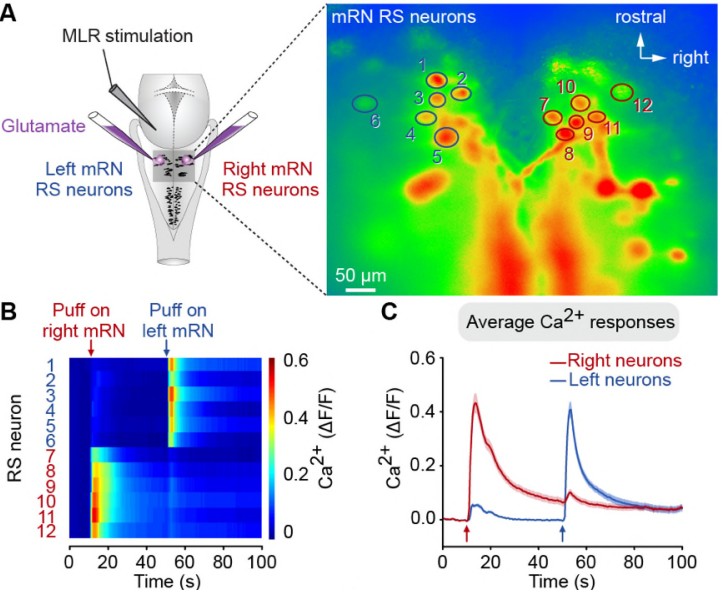

C Average $\mathrm{Ca}^{2+}$ responses

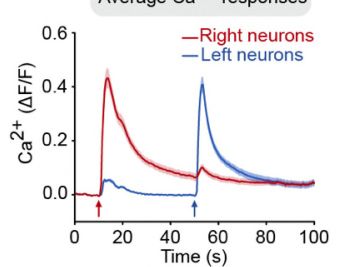

D
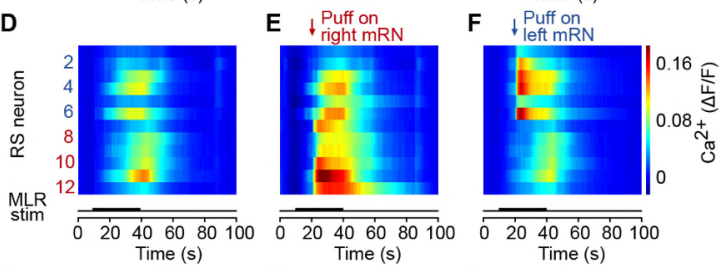

G
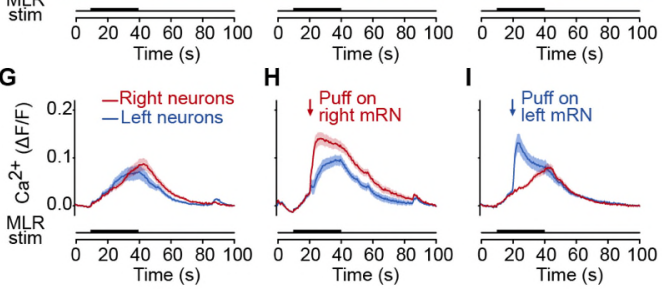

Figure 3. Calcium $\left(\mathrm{Ca}^{2+}\right)$ signals corresponding to steering commands toward left and right sides. A: Left, dorsal view of a salamander brain. Right, fluorescence of left (circled in blue) and right (circled in red) reticulospinal (RS) cells of the middle reticular nucleus $(\mathrm{mRN})$ at rest. B-C: Raw (B) and average \pm sem (C) $\mathrm{RS} \mathrm{Ca}^{2+}$ responses evoked by microinjections (arrows) of 0.27 to 1.14 pmol of glutamate $(2.5 \mathrm{mM}, 3$ pulses, $2 \mathrm{~Hz}, 20$ or $50 \mathrm{~ms}$ pulses, 3-4 PSI, $0.45-0.11 \mathrm{~nL}$ per injection) on the right or left sides of the mRN. D-I: Effect of the glutamate microinjections (arrows) on the bilaterally symmetrical $\mathrm{RS} \mathrm{Ca}^{2+}$ responses (D-E, raw; G-H, average \pm sem) evoked by unilateral stimulation of the Mesencephalic Locomotor Region (MLR, $30 \mathrm{~s}$ train, $5 \mathrm{~Hz}, 2 \mathrm{~ms}$ pulses, $3 \mu \mathrm{A}$ ).

$\mathrm{Ca}^{2+}$ responses evoked by local microinjection of $\mathrm{D}, \mathrm{L}-$ glutamate. Glass micropipettes were placed on each side of the $\mathrm{mRN}$ to perform microinjections of 0.27 to $1.14 \mathrm{pmol}$ of D,L-glutamate (2.5 mM, 3-10 pulses, $2 \mathrm{~Hz}, 3-4$ PSI, 20-50 ms pulses, 0.11-0.45 nL per injection) over the left or right $\mathrm{mRN}$ (Fig. 3A). Glutamate microinjection over the left $\mathrm{mRN}$ selectively evoked $\mathrm{Ca}^{2+}$ responses in left $\mathrm{RS}$ neurons (Fig. 3B-C). Conversely, microinjections on the right side evoked selective response in right RS neurons (Fig. 3B-C). In both cases, much smaller responses were evoked in RS cells contralateral to the injection site. These were likely evoked either by partial spreading of glutamate contralaterally to the injection site or by possible excitatory cross-connections between RS cells. Altogether this indicated that the bending responses evoked in the semi-intact preparation were most likely evoked by a stronger activation of the RS cells located ipsilateral to the bending.

We then asked whether such selective RS activation on one side is sufficient to generate an asymmetry in the MLRevoked locomotor command. As previously shown in salamanders [31], MLR stimulation (30 s train, $5 \mathrm{~Hz}, 2 \mathrm{~ms}$ pulses, $1.5-3 \mu \mathrm{A}$ ) evoked a bilaterally symmetrical activation
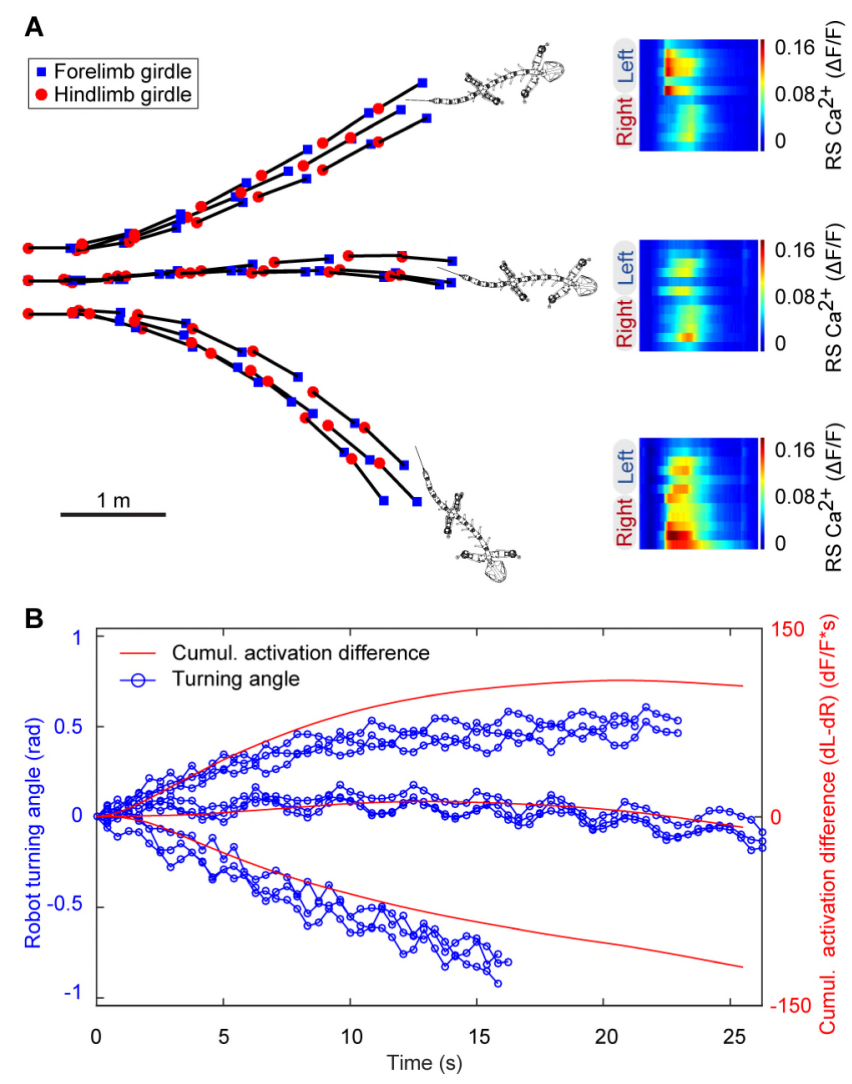

Figure 4. Control of robot direction with reticulospinal (RS) $\mathrm{Ca}^{2+}$ activity. A: Trajectories of Pleurobot when driven by the three $\mathrm{RS} \mathrm{Ca}^{2+}$ responses shown in Fig. 3G-I. B: Time evolution of the turning angle in comparison with the cumulative sum of the difference of left and right RS signals.

of RS cells of the $m R N(n=2$ preparations, Fig. $3 G)$. Such activation is consistent with the MLR being a structure generating symmetrical locomotor movements in lampreys [41], salamanders [30], and cats [51]. When a selective microinjection of 0.27 to $1.89 \mathrm{pmol}$ of D,L-glutamate $(2.5$ $\mathrm{mM}, 3-5$ pulses, $2 \mathrm{~Hz}$, 3-4 PSI, 20-50 ms pulses, 0.11-0.76 $\mathrm{nL}$ per injection) over the right $\mathrm{mRN}$ was superimposed to MLR stimulation, we observed an increased $\mathrm{RS} \mathrm{Ca}^{2+}$ response ipsilaterally to the injection site (Fig. 3H). Conversely, when glutamate was injected selectively over the left $\mathrm{mRN}$, an increased $\mathrm{Ca}^{2+}$ response was observed in the left mRN RS cells (Fig. 3I). Altogether these results suggest that glutamatergic inputs to RS neurons can bias the MLR locomotor command toward the right or the left side. Such a phenomenon suggests that RS cells can integrate the locomotor command and steering-related inputs. Thus, the activity of these neurons is interesting to interface with a locomotor device in order to control speed and direction.

\section{Control of robot direction with brainstem signals}

We then used the locomotor commands from the RS cells to control Pleurobot driven by a spinal cord and brainstem model. The descending drives to the left and right sides of the spinal cord model were computed as mean RS cell activations on the left and right sides, respectively. The robot experiments were carried out for three different RS $\mathrm{Ca}^{2+}$ responses (Fig. 3G-I), that would correspond to straight motion, right and left turn, respectively. Each experiment 
A

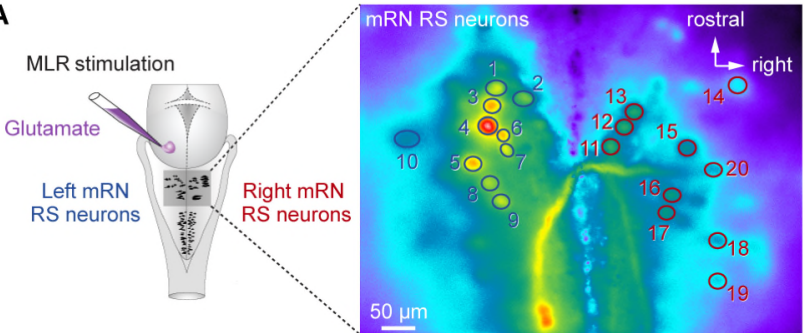

B
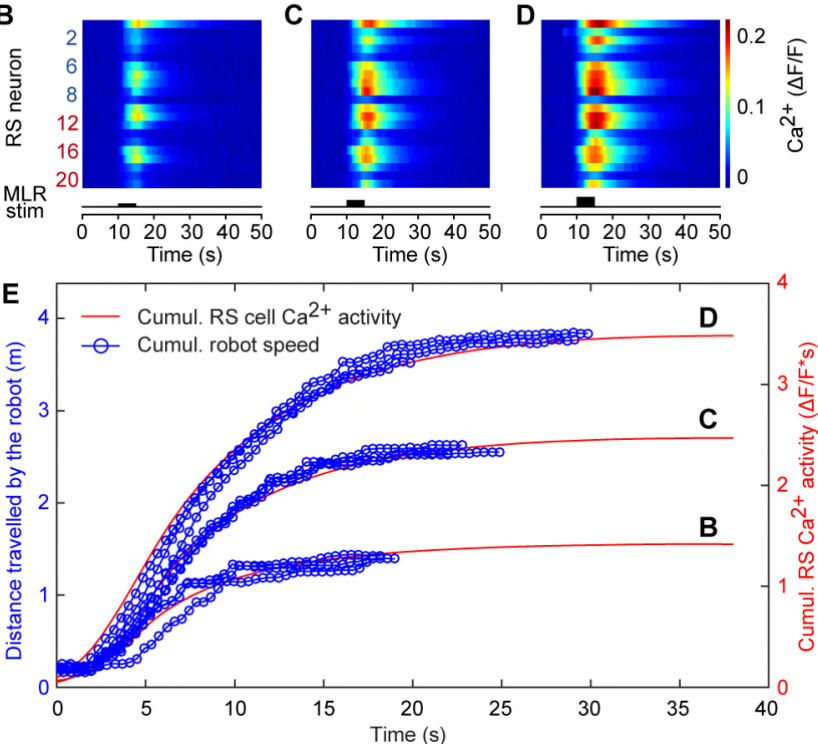

Figure 5. Control of robot speed with reticulospinal (RS) $\mathrm{Ca}^{2+}$ activity. A: Microinjections over the MLR of a solution of Ringer's containing D,Lglutamate $(2.5 \mathrm{mM})$ was used to evoke bilateral $\mathrm{Ca}^{2+}$ response in RS cells of the middle reticular nucleus (mRN) as previously reported [31]. B-D: Gradual increase of the RS $\mathrm{Ca}^{2+}$ responses on both sides of the mRN following microinjections of $2.26 \mathrm{pmol}(\mathrm{B}), 3.78 \mathrm{pmol}(\mathrm{C})$, or $7.84 \mathrm{pmol}$ (D) of D,L-glutamate (2.5 mM, 10 pulses, $2 \mathrm{~Hz}, 40-60 \mathrm{~ms}$ pulses, 3-4 PSI, $0.91,1.51$ and $3.13 \mathrm{~nL}$ respectively). E: Control of locomotor speed by the amplitude of the $\mathrm{Ca}^{2+}$ RS responses evoked by MLR stimulation of increasing strengths. For each trial illustrated in B-D, the cumulative distance travelled by the robot is illustrated as a function time. The stronger MLR stimulations allowed the robot to travel a longer distance during the same amount of time.

was repeated three times to test the variability of the robot kinematics depending on the given biological drives. We observed that all three behaviors could be generated with the robot (Fig. 4A). Furthermore, Pleurobot could handle the commanded signals very robustly. This is indicated by the small variability in the resulting robot trajectories for a given biological RS drive. Fig. 4B characterizes the turning with respect to the differential $\mathrm{Ca}^{2+}$ response recorded in left and right $\mathrm{RS}$ neurons.

\section{Control of robot speed with brainstem signals}

The strength of MLR activation controls locomotor speed in all vertebrate tested (for review see [19]), including salamanders [30]. This phenomenon was recently related to the ability of the MLR to very precisely control the amplitude of RS responses in salamanders [31]. We thus asked whether the RS activity driven by MLR stimulation could be used to control robot speed. For this experiment, we used one single preparation in which the MLR was chemically stimulated with gradually increasing amounts of glutamate (2.26 to 7.84 pmol of D,L-glutamate $(2.5 \mathrm{mM}, 10$ pulses, $2 \mathrm{~Hz}, 3-4$ PSI, 40-60 ms pulses, 0.31-0.91 nL per injection)) (Fig. 5A). Such stimulation evokes a bilaterally symmetrical activation of RS neurons as recently demonstrated in salamanders [31] (Fig. 5B-D). The goal here was to correlate the level of RS activation to the speed of the robot. We compared the cumulative RS activation over time with the forward progression of the robot, i.e. the distance travelled by the robot during the same amount of time when driven by RS signals of different amplitudes (Fig. $5 \mathrm{E})$. The relative $\mathrm{RS}$ cell activation changes were consistent with the changes in robot speeds, thus indicating that the $\mathrm{Ca}^{2+}$ responses could be indeed used for speed control.

\section{DISCUSSION}

The present work demonstrates that $\mathrm{Ca}^{2+}$ signals from a population of brainstem RS neurons can be used to control off-line, but in real time, the speed and direction of a robot driven by a brainstem and spinal cord model.

BMIs are rarely designed on the basis of optical recordings of neuronal $\mathrm{Ca}^{2+}$ signals. To our knowledge, only one study used such an approach, to make mice learn to modulate neural activity in response to auditory feedback. The authors used transgenic mice expressing a $\mathrm{Ca}^{2+}$ indicator in cortical neurons [52]. Traditionally, multiple extracellular recordings of large population of neurons are used to control BMIs. In comparison with spiking activity, $\mathrm{Ca}^{2+}$ signals show slower dynamics, and could be seen as a smoothed average of spiking frequency. A classical caveat with $\mathrm{Ca}^{2+}$ based measurements of neuronal activity is to determine whether the signal represents spiking or subthreshold activity. Electrophysiological recordings coupled with $\mathrm{Ca}^{2+}$ imaging of the same neuron (with the same $\mathrm{Ca}^{2+}$ indicator than the one used in the present study) revealed that a 0.09 increase in $\Delta \mathrm{F} / \mathrm{F}$ is associated with spiking [53], [54], and this is consistent with recent observations in salamanders (see [31]). This would indicate that most RS cells illustrated in e.g. Fig. 3 and 5 spike action potentials when stimulated by MLR and/or glutamate injections. On the other hand, the advantage of our approach compared to a microelectrode array is that we have a resolution at the single cell level for a population of identified neurons. In the present study we used a very simple left/right population averaging approach to control the robot. However, a more cell-specific coding could very well be implemented, since the recorded cells are easily trackable. The $\mathrm{Ca}^{2+}$ approach also allows the experimenter to spot the activity of rarely active cell that are hard to detect with extracellular recordings [55]. Importantly, the recently developed miniaturized microscopes $(1.9 \mathrm{~g})$ now makes $\mathrm{Ca}^{2+}$ imaging usable in freely moving animals [56]. Similar $\mathrm{Ca}^{2+}$ imaging systems could be used in the future in humans.

Here we show that unilateral stimulation of the RS cells elicits ipsilateral body bending at rest. Future work should determine whether unilateral RS stimulation elicits turning during locomotion in the semi-intact preparation. This is very likely, since unilateral increase in RS activity was reported during turning in lampreys [21]. The spinal targets of the RS neurons recorded in the present study also remain to be characterized. Furthermore, the origin of the excitatory 
glutamatergic inputs responsible for increasing the RS activity during turning remains to be determined in salamanders. In lampreys, RS neurons receive excitatory inputs from several regions including the MLR and spinal cord (for review see [22]), but also sensory modalities like e.g. the vestibular and visual systems (e.g. for the visual system see [50]). Our next step is to close the loop and add feedback from the robot to the salamander brain. The brain will interact online with the robot, and we will investigate whether this can lead to visually-guided motor behaviors such as obstacle avoidance and following a visual stimulus.

Finally, our work could be viewed through the prism of assistive technology. BMIs are now increasingly used in the field of rehabilitation robotics. Our work suggests that brainstem locomotor networks could be used to control speed and direction of a locomotor device, like a lower limb exoskeleton. The advantage of our approach compared to previous studies relying on forelimb EMGs or cortical recording is that interfacing at the brainstem level allows us to record important information concerning locomotor speed and direction. In this context, it is noteworthy that in humans asked to imagine they are walking, an increased activity is detected in brainstem locomotor networks, including the MLR [57], [58]. Another difference between our approach compared to the previous ones is that, in contrast with cortical activity where the desired activity has to be learned by the patient to fit at best with the degrees of freedom of the robot, the activity of brainstem network could be used more "naturally" to control a locomotor device by thought. However, it should be noted that these networks, located deep in the brain, are hard to reach. Nevertheless, brainstem locomotor networks are increasingly targeted by clinicians in the context of deep brain stimulation, in order to improve locomotor function in patients with Parkinson's disease [59], [60]. The recent discovery in rodents that MLR stimulation enhances locomotor recovery after spinal cord injury might soon open a new way to improve locomotor function in patients suffering from such devastating injuries [61].

\section{CONCLUSION}

Our work shows that $\mathrm{Ca}^{2+}$ signals from brainstem neurons can be used to control the speed and direction of locomotion of a robot driven by a brainstem and spinal cord model.

\section{ACKNOWLEDGMENT}

The authors thank Jean-Marie Cabelguen for useful discussions on locomotor control in salamanders. D.R. thanks Réjean Dubuc for generously providing access to the experimental setup used in the present study. R. T. and A. J. I. thank Tomislav Horvat for advice on the robot control, and in particular the inverse kinematics implementation.

\section{REFERENCES}

[1] A. P. Georgopoulos, R. E. Kettner, and A. B. Schwartz, "Neuronal population coding of movement direction," Science, vol. 233, pp. 1416-1419, 1986.

[2] L.E. Sergio and J.F. Kalaska, "Changes in the temporal pattern of primary motor cortex activity in a directional isometric force versus limb movement task," J Neurophysiol, vol. 80, pp. 1577-1583, 1998.
[3] J.K. Chapin, K.A. Moxon, R.S. Markowitz, M.A. Nicolelis, "Realtime control of a robot arm using simultaneously recorded neurons in the motor cortex," Nat Neurosci, vol. 7, pp. 664-670, 1999.

[4] M. A. Lebedev, J. M. Carmena, J. E. O’Doherty, M. Zacksenhouse, C. S. Henriquez, J. C. Principe, and M. A. L. Nicolelis, "Cortical ensemble adaptation to represent velocity of an artificial actuator controlled by a brain-machine interface," J Neurosci, vol. 25, pp. 4681-4693, 2005.

[5] M. Velliste, S. Perel, M.C. Spalding, A.S. Whitford, A.B. Schwartz, "Cortical control of a prosthetic arm for self-feeding," Nature, vol. 453, pp. 1098-1101, 2008.

[6] L.R. Hochberg, D. Bacher, B. Jarosiewicz, N.Y. Masse, J.D. Simeral, J. Vogel, S. Haddadin, J. Liu, S.S. Cash, P. van der Smagt, J.P. Donoghue, "Reach and grasp by people with tetraplegia using a neurally controlled robotic arm," Nature, vol. 485, pp. 372-375, 2012.

[7] J.L. Collinger, B. Wodlinger, J.E. Downey, W. Wang, E.C. TylerKabara, D.J. Weber, A.J. McMorland, M. Velliste, M.L. Boninger, A.B. Schwartz, "High-performance neuroprosthetic control by an individual with tetraplegia," Lancet, vol. 381, pp. 557-564, 2013.

[8] J. He, C. Ma, R. Herman, "Engineering Neural Interfaces for Rehabilitation of Lower Limb Function in Spinal Cord Injured," Proceedings of the IEEE, vol. 96, pp.1152-1166, 2008.

[9] N. Fitzsimmons, M. Lebedev, I. Peikon, M.A. Nicolelis, "Extracting kinematic parameters for monkey bipedal walking from cortical neuronal ensemble activity," Front Integr Neurosci, vol. 3, pp 3, 2009.

[10] A. Manohar, R. D. Flint, E. Knudsen, and K. A. Moxon, "Decoding hindlimb movement for a brain machine interface after a complete spinal transection," PLoS One, vol. 7, p. e52173, 2012.

[11] W. Song, A. Ramakrishnan, U. I. Udoekwere, and S. F. Giszter*, "Multiple Types of Movement-Related Information Encoded in Hindlimb/Trunk Cortex in Rats and Potentially Available for BrainMachine Interface Controls," IEEE Transactions on Biomedical Engineering, vol. 56, pp. 2712-2716, 2009.

[12] M. Alam, X. Chen, Z. Zhang, Y. Li, and J. He, "A brain-machinemuscle interface for restoring hindlimb locomotion after complete spinal transection in rats," PLoS One, vol. 9, p. e103764, 2014.

[13] P. Gad, J. Woodbridge, I. Lavrov, H. Zhong, R. R. Roy, M. Sarrafzadeh, et al., "Forelimb EMG-based trigger to control an electronic spinal bridge to enable hindlimb stepping after a complete spinal cord lesion in rats," J Neuroeng Rehabil, vol. 9, p. 38, 2012.

[14] M. A. Lebedev, A. J. Tate, T. L. Hanson, Z. Li, J. E. O'Doherty, J. A. Winans, et al., "Future developments in brain-machine interface research," Clinics (Sao Paulo), vol. 66 Suppl 1, pp. 25-32, 2011.

[15] A. Presacco, L. W. Forrester, and J. L. Contreras-Vidal, "Decoding intra-limb and inter-limb kinematics during treadmill walking from scalp electroencephalographic (EEG) signals," IEEE Trans Neural Syst Rehabil Eng, vol. 20, pp. 212-9, Mar 2012.

[16] W. Widajewicz, B. Kably, and T. Drew, "Motor cortical activity during voluntary gait modifications in the cat. II. Cells related to the hindlimbs," J Neurophysiol, vol. 72, pp. 2070-89, Nov 1994.

[17] T. Drew, W. Jiang, and W. Widajewicz, "Contributions of the motor cortex to the control of the hindlimbs during locomotion in the cat," Brain Res Brain Res Rev, vol. 40, pp. 178-91, Oct 2002.

[18] L. M. Bjursten, K. Norrsell, and U. Norrsell, "Behavioural repertory of cats without cerebral cortex from infancy," Exp Brain Res, vol. 25, pp. 115-30, May 281976.

[19] D. Ryczko and R. Dubuc, "The multifunctional mesencephalic locomotor region," Curr Pharm Des, vol. 19, pp. 4448-70, 2013.

[20] M. L. Shik, F. V. Severin, and G. N. Orlovskii, "[Control of walking and running by means of electric stimulation of the midbrain]," Biofizika, vol. 11, pp. 659-66, 1966.

[21] T. G. Deliagina, P. V. Zelenin, P. Fagerstedt, S. Grillner, and G. N. Orlovsky, "Activity of reticulospinal neurons during locomotion in the freely behaving lamprey," J Neurophysiol, vol. 83, pp. 853-63, Feb 2000.

[22] R. Dubuc, F. Brocard, M. Antri, K. Fenelon, J. F. Gariepy, R. Smetana, et al., "Initiation of locomotion in lampreys," Brain Res Rev, vol. 57, pp. 172-82, Jan 2008.

[23] A. Karniel, M. Kositsky, K. M. Fleming, M. Chiappalone, V. Sanguineti, S. T. Alford, et al., "Computational analysis in vitro: dynamics and plasticity of a neuro-robotic J Neural Eng system,", vol. 2, pp. S250-65, Sep 2005. 
[24] M. Kositsky, A. Karniel, S. Alford, K. M. Fleming, and F. A. MussaIvaldi, "Dynamical dimension of a hybrid neurorobotic system," IEEE Trans Neural Syst Rehabil Eng, vol. 11, pp. 155-9, Jun 2003.

[25] S. Grillner "Control of locomotion in bipeds, tetrapods, and fish". In Handbook of Physiology, The Nervous System II, Motor Control, Vol. 2, ed. Bethesda, V.B.B., 1179-1236. American Physiological Society, 1981 .

[26] J. Cheng, R. B. Stein, K. Jovanovic, K. Yoshida, D. J. Bennett, and Y. Han, "Identification, localization, and modulation of neural networks for walking in the mudpuppy (Necturus maculatus) spinal cord," $J$ Neurosci, vol. 18, pp. 4295-304, Jun 11998.

[27] I. Delvolve, P. Branchereau, R. Dubuc, and J. M. Cabelguen, "Fictive rhythmic motor patterns induced by NMDA in an in vitro brain stemspinal cord preparation from an adult urodele," J Neurophysiol, vol. 82, pp. 1074-7, Aug 1999.

[28] D. Ryczko, V. Charrier, A. Ijspeert, and J. M. Cabelguen, "Segmental oscillators in axial motor circuits of the salamander: distribution and bursting mechanisms," J Neurophysiol, vol. 104, pp. 2677-92, Nov 2010.

[29] D. Ryczko, J. Knusel, A. Crespi, S. Lamarque, A. Mathou, A. J. Ijspeert, et al., "Flexibility of the axial central pattern generator network for locomotion in the salamander," J Neurophysiol, vol. 113, pp. 1921-40, Mar 152015.

[30] J. M. Cabelguen, C. Bourcier-Lucas, and R. Dubuc, "Bimodal locomotion elicited by electrical stimulation of the midbrain in the salamander Notophthalmus viridescens," $J$ Neurosci, vol. 23, pp. 2434-9, Mar 152003.

[31] D. Ryczko, F. Auclair, J. M. Cabelguen, and R. Dubuc, "The mesencephalic locomotor region sends a bilateral glutamatergic drive to hindbrain reticulospinal neurons in a tetrapod," J Comp Neurol, Oct 162015 .

[32] C. Naujoks-Manteuffel and G. Manteuffel, "Origins of descending projections to the medulla oblongata and rostral medulla spinalis in the urodele Salamandra salamandra (amphibia)," J Comp Neurol, vol. 273, pp. 187-206, Jul 81988.

[33] C. Sanchez-Camacho, O. Marin, H. J. Ten Donkelaar, and A. Gonzalez, "Descending supraspinal pathways in amphibians. I. A dextran amine tracing study of their cells of origin," J Comp Neurol, vol. 434, pp. 186-208, May 282001.

[34] C. S. Hubbard, E. K. Dolence, and J. D. Rose, "Brainstem reticulospinal neurons are targets for corticotropin-releasing factorInduced locomotion in roughskin newts," Horm Behav, vol. 57, pp. 237-46, Feb 2010.

[35] C. A. Lowry, J. D. Rose, and F. L. Moore, "Corticotropin-releasing factor enhances locomotion and medullary neuronal firing in an amphibian," Horm Behav, vol. 30, pp. 50-9, Mar 1996.

[36] I. Bar-Gad, I. Kagan, and M. L. Shik, "Behavior of hindbrain neurons during the transition from rest to evoked locomotion in a newt," Prog Brain Res, vol. 123, pp. 285-94, 1999.

[37] I. Kagan and M. L. Shik, "How the mesencephalic locomotor region recruits hindbrain neurons," Prog Brain Res, vol. 143, pp. 221-30, 2004.

[38] A. J. Ijspeert, A. Crespi, D. Ryczko, and J. M. Cabelguen, "From swimming to walking with a salamander robot driven by a spinal cord model," Science, vol. 315, pp. 1416-20, Mar 92007.

[39] A. Bicanski, D. Ryczko, J. M. Cabelguen, and A. J. Ijspeert, "From lamprey to salamander: an exploratory modeling study on the architecture of the spinal locomotor networks in the salamander," Biol Cybern, vol. 107, pp. 565-87, Oct 2013.

[40] J. Knusel, A. Bicanski, D. Ryczko, J. M. Cabelguen, and A. J. Ijspeert, "A salamander's flexible spinal network for locomotion, modeled at two levels of abstraction," Integr Comp Biol, vol. 53, pp. 269-82, Aug 2013.

[41] F. Brocard, D. Ryczko, K. Fenelon, R. Hatem, D. Gonzales, F. Auclair, et al., "The transformation of a unilateral locomotor command into a symmetrical bilateral activation in the brainstem," $J$ Neurosci, vol. 30, pp. 523-33, Jan 132010.

[42] D. Derjean, A. Moussaddy, E. Atallah, M. St-Pierre, F. Auclair, S. Chang, et al., "A novel neural substrate for the transformation of olfactory inputs into motor output," PLoS Biol, vol. 8, p. e1000567, 2010.
[43] J. F. Gariepy, K. Missaghi, S. Chevallier, S. Chartre, M. Robert, F. Auclair, et al., "Specific neural substrate linking respiration to locomotion," Proc Natl Acad Sci U S A, vol. 109, pp. E84-92, Jan 10 2012.

[44] D. Ryczko, S. Gratsch, F. Auclair, C. Dube, S. Bergeron, M. H. Alpert, et al., "Forebrain dopamine neurons project down to a brainstem region controlling locomotion," Proc Natl Acad Sci U S A, vol. 110, pp. E3235-42, Aug 202013.

[45] A. J. Ijspeert, "A connectionist central pattern generator for the aquatic and terrestrial gaits of a simulated salamander," Biol Cybern, vol. 84, pp. 331-48, May 2001.

[46] N. Harischandra, J. M. Cabelguen, and O. Ekeberg, "A 3D MusculoMechanical Model of the Salamander for the Study of Different Gaits and Modes of Locomotion," Front Neurorobot, vol. 4, p. 112, 2010.

[47] T. Horvat, K. Karakasiliotis, K. Melo, L. Fleury, R. Thandiackal, and A.J. Ijspeert, "Inverse kinematics and reflex based controller for bodylimb coordination of a salamander-like robot walking on uneven terrain," in International Conference on Intelligent Robots and Systems (IROS) 2015 IEEE/RSJ, pp. 195-201.

[48] P. Fagerstedt, G. N. Orlovsky, T. G. Deliagina, S. Grillner, and F Ullen, "Lateral turns in the Lamprey. II. Activity of reticulospinal neurons during the generation of fictive turns," J Neurophysiol, vol. 86, pp. 2257-65, Nov 2001.

[49] G. Roth, U. Dicke, and W. Grunwald, "Morphology, axonal projection pattern, and response types of tectal neurons in plethodontid salamanders. II: intracellular recording and labeling experiments," $J$ Comp Neurol, vol. 404, pp. 489-504, Feb 221999.

[50] K. Saitoh, A. Menard, and S. Grillner, "Tectal control of locomotion, steering, and eye movements in lamprey," J Neurophysiol, vol. 97, pp. 3093-108, Apr 2007.

[51] P. E. Musienko, P. V. Zelenin, V. F. Lyalka, Y. P. Gerasimenko, G. N. Orlovsky, and T. G. Deliagina, "Spinal and supraspinal control of the direction of stepping during locomotion," J Neurosci, vol. 32, pp. 17442-53, Nov 282012.

[52] K. B. Clancy, A. C. Koralek, R. M. Costa, D. E. Feldman, and J. M. Carmena, "Volitional modulation of optically recorded calcium signals during neuroprosthetic learning," Nat Neurosci, vol. 17, pp. 807-9, Jun 2014.

[53] D. H. Bhatt, D. L. McLean, M. E. Hale, and J. R. Fetcho, "Grading movement strength by changes in firing intensity versus recruitment of spinal interneurons," Neuron, vol. 53, pp. 91-102, Jan 42007.

[54] W. C. Wang and D. L. McLean, "Selective responses to tonic descending commands by temporal summation in a spinal motor pool," Neuron, vol. 83, pp. 708-21, Aug 62014.

[55] S. Shoham, D. H. O'Connor, and R. Segev, "How silent is the brain: is there a "dark matter" problem in neuroscience?," J Comp Physiol A Neuroethol Sens Neural Behav Physiol, vol. 192, pp. 777-84, Aug 2006.

[56] KK Ghosh, LD Burns, ED Cocker, A Nimmerjahn, Y Ziv, AE Gamal, MJ Schnitzer, "Miniaturized integration of a fluorescence microscope." Nat Methods, vol.8, pp 871-8, Sep 112011.

[57] K. Jahn, A. Deutschlander, T. Stephan, R. Kalla, M. Wiesmann, M. Strupp, et al., "Imaging human supraspinal locomotor centers in brainstem and cerebellum," Neuroimage, vol. 39, pp. 786-92, Jan 15 2008

[58] C. Karachi, D. Grabli, F. A. Bernard, D. Tande, N. Wattiez, H. Belaid, et al., "Cholinergic mesencephalic neurons are involved in gait and postural disorders in Parkinson disease," J Clin Invest, vol. 120, pp. 2745-54, Aug 2010.

[59] P. Plaha and S. S. Gill, "Bilateral deep brain stimulation of the pedunculopontine nucleus for Parkinson's disease," Neuroreport, vol. 16, pp. 1883-7, Nov 282005.

[60] P. Mazzone, A. Lozano, P. Stanzione, S. Galati, E. Scarnati, A. Peppe, et al., "Implantation of human pedunculopontine nucleus: a safe and clinically relevant target in Parkinson's disease," Neuroreport, vol. 16, pp. 1877-81, Nov 282005.

[61] L. C. Bachmann, A. Matis, N. T. Lindau, P. Felder, M. Gullo, and M. E. Schwab, "Deep brain stimulation of the midbrain locomotor region improves paretic hindlimb function after spinal cord injury in rats," Sci Transl Med, vol. 5, p. 208ra146, Oct 232013. 